\title{
Effect of the Etching on Chemical Mechanical Planarization of the Selective Layer Surface
}

\author{
Filip Ilie \\ Department of Machine Elements and Tribology, Polytechnic University of Bucharest, Bucharest, Romania
}

\section{Email address:}

ilie.filip@yahoo.com

\section{To cite this article:}

Filip Ilie. Effect of the Etching on Chemical Mechanical Planarization of the Selective Layer Surface. International Journal of Materials Science and Applications. Vol. 6, No. 4, 2017, pp. 193-199. doi: 10.11648/j.ijmsa.20170604.15

Received: June 19, 2017; Accepted: June 28, 2017; Published: July 17, 2017

\begin{abstract}
Among other the planarization technologies, Chemical mechanical planarization (CMP) is the unique global planarization technology, which makes it be continuously investigated. The planarization (polishing) and micromachining are of considerable interest to different engineering fields, such as the friction couples that function with the selective transfer and is used to remove excess of metal, obtained in process of selective transfer and for the understanding of planarization and micromachining. For an effective planarization, it is necessary to minimize the surface defects while attaining a good planarity with optimal material removal rate (MRR). These requirements can be met by controlling the chemical and mechanical interactions during the polishing process, or by engineering the slurry chemistry, particles properties, and stability. Effect of the etching during CMP process of the selective layer surface are presented in this paper. To optimize the process of selective layer CMP a blanket selective layer samples were polished with, colloidal silica-based slurry which contains a citric acid and an oxidizer $\left(\mathrm{H}_{2} \mathrm{O}_{2}\right)$. Surface studies using X-ray photoelectron spectroscopy (XPS) were performed on selective layer samples after chemical etching in order to determine the effect that different polishing parameters (i.e., $\mathrm{pH}$ and $\mathrm{H}_{2} \mathrm{O}_{2}$ concentration) have on the selective layer surface. Then, the samples were passively soaked in an acidic slurry mixture containing different concentrations of $\mathrm{H}_{2} \mathrm{O}_{2}$ to determine how the chemical action alone affects the removal of the selective layer. The etching results revealed that a cuprous oxide $\left(\mathrm{Cu}_{2} \mathrm{O}\right)$ forms on the surface of the etched metallic selective layer while polished samples showed $\mathrm{CuO}$ and $\mathrm{Cu}(\mathrm{OH})_{2}$. The effect of these selective layer oxide films on the removal of the selective layer in passive etching and CMP is discussed.
\end{abstract}

Keywords: Selective Layer, Etching, Chemical Mechanical Planarization, Slurry, X-Ray Photoelectron Spectroscopy

\section{Introduction}

To understand the surface properties of layers formed by selective transfer, it must be specified that there are materials which under optimal functioning conditions form a thin, superficial layer of copper in the contact areas, and therefore, can function in conditions of selective transfer. These materials have in common the fact that, in the friction areas, special physic-chemical processes take place, which leads to the formation of a thin copper layer, almost pure, with superior properties at minimal friction and wear [1-3]. In the process of friction of these materials and in the presence of own lubricants, wear phenomenon itself manifests as a transfer of material from an element of a friction couple on the other, this phenomenon being characteristic to the selective transfer process. A selective transfer can be safely achieved in a friction couple in the presence of relative movement if there is a favorable energy, in the friction area is a material made by copper and the lubricant is adequate (glycerin or special lubricant).

Studying the selective layer CMP, of which the predominant one is copper (in the proportion of over 85 per cent), it is found that in normal conditions, selective layer surface is oxidized, and removing the surface oxide layer in different rates, depending on the depth of removal and the $\mathrm{pH}$ of the solution.

CMP is a surface smoothing and material removal process, made possible by the combination of chemical and mechanical interactions. The wafer surface (on which transferred selective layer are to be built) is planarized by a slurry consisting of nanometric sized abrasive particles and chemical reagents. The ultimate goal of CMP is to achieve an 
optimal material removal rate creating an atomically smooth surface with a minimal number of defects while maintaining global planarity. The chemical effect in CMP is provided by the $\mathrm{pH}$ slurry, oxidizers or stabilizers. The mechanical action is mostly provided by the nanometric sized abrasive particles contained in the slurry, as they flow between the polishing pad and the wafer surface.

To obtain a surface with higher resolution and planarization and the minimal deformations [4], is requires close monitoring of the CMP process that can be attained by controlling not only the operational variables (such as the applied head pressure and the relative pad velocity) but also the slurry particles properties.

CMP removes material by rotating a metal or wafer coated by selective transfer and pressing its active surface against a rotating polymer-based pad filled with abrasive slurry particles. Chemical reagents in the slurry mixture are added to enhance the removal rate of the particular material being polished and/or to passivate the low-lying regions on the wafer. Surface flatness results from high points on the sample being polished at a higher rate than the polishing rate for lower lying ones.

Although the basic principles of CMP are understood, the process remains un-optimized for selective layer CMP because the exact mechanism of selective layer removal during polishing and the necessary surface chemical processes are still unknown. The selective layer CMP process is poorly understood, due mainly to electrochemical interactions between the slurry and selective layer film during polishing, and the coupled effect of these on the mechanical properties of the surface. To better understand how the selective layer is removed during CMP, initial studies were performed in the present paper to examine the effects on which the chemical component alone has on the surface of the selective layer.

Chemical state of selective layer surface and the $\mathrm{pH}$ of the slurries play a very important role in the selective layer CMP removal process. The present paper explores the effect of $\mathrm{pH}$ and $\mathrm{H}_{2} \mathrm{O}_{2}$ on the etching behavior of selective layer.

Selective layer samples were exposed to various slurry mixtures of different $\mathrm{pH}$ containing different $\mathrm{H}_{2} \mathrm{O}_{2}$ concentrations without mechanical action for certain exposure times. XPS is an important surface analytical tool that can be used to identify the compound formed on the metal surface due to the action of chemical present in CMP slurry. XPS was used to determine how the different components of the slurry modified the selective layer surface and how these modifications affect the etching of selective layer. The effects of these surface modifications during the CMP process are discussed.

\section{Experimental Details}

The results described in this paper were obtained using a
CP-4 CMP planarization tool with a wafer carrier that was modified to polish partial selective layer samples $20 \times 20$ $\mathrm{mm}$ in size. The CMP polisher used in this experiment was a rotational type that uses air pressure for pressing the wafer against the polishing pad attached to the platen. The force on the wafer or sample is set by air pressure applied uniformly to the wafer carrier via a tube connected to an air supply source. In this study, the pressure and the linear polishing velocity were kept constant at $20 \mathrm{kPa}$ and $30 \mathrm{~m} / \mathrm{min}(0.5$ $\mathrm{m} / \mathrm{s}$ ), respectively. The $\mathrm{CP}-4 \mathrm{CMP}$ planarization tool is equipped in-situ with a monitoring system (sensors). The signals from the sensors were amplified through an amplifier and then transferred to a data acquisition system.

Polishing was performed on $20 \times 20 \mathrm{~mm}$ samples cleaved from a $200 \mathrm{~mm}$ diameter patterned wafer from metal with the selective layer (OLC45 steel coated with the selective layer formed in the friction process with the CuSn12T bronze). The thickness of the selective layer films was obtained by examining of four-point probe and measurement the resistance of the blanket selective layer film at the center of the cleaved samples.

Slurry consists in its premixed form of $3.0 \mathrm{wt} . \%$ fumed colloidal silica particles with a median particle diameter of $250 \mathrm{~nm}$, and a citric acid which is commonly used in metallic selective layer CMP slurries as a buffering or complexing agent $[5,6] . \mathrm{H}_{2} \mathrm{O}_{2}$ was added to the premixed slurry to oxidize the selective layer (copper from the selective layer) and enhance its removal. For the oxidizer concentration experiments, the concentration of the $\mathrm{H}_{2} \mathrm{O}_{2}$ was varied between 0.0 and 6.0 vol. $\%$ by diluting 30 vol. $\% \mathrm{H}_{2} \mathrm{O}_{2}$ with deionized water. The $\mathrm{pH}$ of the final slurry mixture (silica abrasive + citric acid $+\mathrm{H}_{2} \mathrm{O}_{2}$ ) was kept constant or varied. In all slurry mixtures, the abrasive particle concentration was kept constant.

For all planarization runs, the slurry was continually agitated to prevent agglomeration of the solids and pumped to the polishing platen at a flow rate of $200 \mathrm{~mL} / \mathrm{min}$ and 10 $\mathrm{mm}$ selective layer wafers were used. Chemical reagents in the CMP slurry react with the wafer surface, being planarization, forming a chemically modified top layer with desirable properties compared to the initial wafer surface. For example, passivation of the patterned wafer from metallic selective layer oxide film prevents the metallic selective layer etching in the low areas, while the high asperities are repeatedly oxidized by the chemicals and abraded by the slurry particles until the planarization is reached. Thus, slurry oxides provide topographic selectivity in metallic selective layer CMP. In selective layer planarization, the chemical effect is provided by increasing the slurry $\mathrm{pH}$. So, the properties of the chemically modified layer material are expected to be different from those of the polished film, which gives control over the CMP process.

The absence of the chemically modified layer was found, as the result material removal lack, by planarizing [7]. Planarizing mainly by chemical means leaves an isotropically 
etched surface, no planarity, whereas planarizing only by mechanical means a rough surface is obtained. As a result, the formation of a chemically altered film is necessary to achieve an optimal CMP performance and its properties must be tailored by the use of the slurry chemical effective.

After each planarizing run, i.e., as soon as the pressure on the wafer was released, the samples were rinsed with deionized water, carefully removed from the sample holder and dried with compressed nitrogen $\left(\mathrm{N}_{2}\right)$. After drying the sample (about $5 \mathrm{~min}$ ) before the sample was placed into the chamber of the surface analysis tool.

For the dipping experiments, the selective layer samples were pre-planarized and then exposed to dilute sulphuric acid (with $\mathrm{pH} 3$ ) for 3 min to remove any native oxides present on the surface. The samples were then rinsed in deionized water, exposed to the citric acid $-\mathrm{H}_{2} \mathrm{O}_{2}$ mixture, and rinsed in deionized water, and dried with compressed $\mathrm{N}_{2}$. After drying, the sample was placed it in the chamber of the surface analysis tool. Then the samples were immersed in different $\mathrm{pH}$ buffer solutions with $6.0 \% \mathrm{H}_{2} \mathrm{O}_{2}$ for certain time, after which, XPS and SEM examination were carried out. In order to determine the chemical composition of the selective surface after dipping and CMP, samples were placed in an ultrahigh vacuum chamber and analyzed with XPS. The base pressure of the surface analysis chamber of the XPS system was $\sim 0.133 \mathrm{MPa}$ during the runs.

The solid concentration in the slurries was maintained at 4.0 wt.\%. The $\mathrm{pH}$ was adjusted using the standard buffer solutions. The linear velocity was maintained at about 0.5 $\mathrm{m} / \mathrm{s}$. The applied downward pressure was about $0.133 \mathrm{MPa}$. The polishing time for each run was $5 \mathrm{~min}$ and the polishing rate reported in this study is an average of 3 independent polishing runs.

\section{Results and Discussions}

\subsection{Technical Issues}

In any CMP process, the higher asperities of a sample are polished at a higher rate than the lower asperities if planarization of the surface is to result. To achieve planarization of the metallic selective layer, the pad has to be rigid enough so that it does not bend into the recessed areas of the sample and the slurry has to be achieved such that chemical reagents in the mixture do not etch the low asperities during CMP. The colloidal silica -based acidic slurry used in the present study incorporating $\mathrm{H}_{2} \mathrm{O}_{2}$ as an oxidizer and a citric acid as a $\mathrm{pH}$ buffer shows excellent removal and planarization behavior.

Abrasive CMP slurry particles provide the mechanical action during the polishing process. The chemically modified surface layer of the wafer is abraded continuously with the nanoscale size slurry abrasive particles resulting in the material removal. To achieve an optimal planarization performance with minimal deformations and good planarity, it is necessary optimization the rates of chemical modification and mechanical planarization. The intensity of the mechanical planarization also varies with the slurry particles size and concentration, with the number of slurry abrasive particles in contact with the wafer surface. Therefore, slurry abrasive particle size and concentration, as well as the particle size distribution and the number of the those in contact with the wafer surface (as a factor that determine the load applied per particle), are very important factors in determining the planarizing performance and should be studied carefully to understand the CMP process. A small variation in the slurry particle size distribution by oversize particle contamination or due to slurry destabilization may result in major changes in the particlesubstrate interactions. Therefore, the MRR response may vary resulting in poor process control and the number of surface deformations may increase giving rise to defects micro/nanometric.

To verify the excellent polishing results observed on selective layer wafers, that are also, seen on patterned selective layer samples, the structures were polished with the same slurry used above for selective layer CMP. Thus, Figure 1 shows the static etching rates of polishing selective layer surface with $100 \mathrm{~mm}$ diameter, in slurries with $6.0 \% \mathrm{H}_{2} \mathrm{O}_{2}$, at $20 \mathrm{kPa}$ load pressure, and at different $\mathrm{pH}$ values.

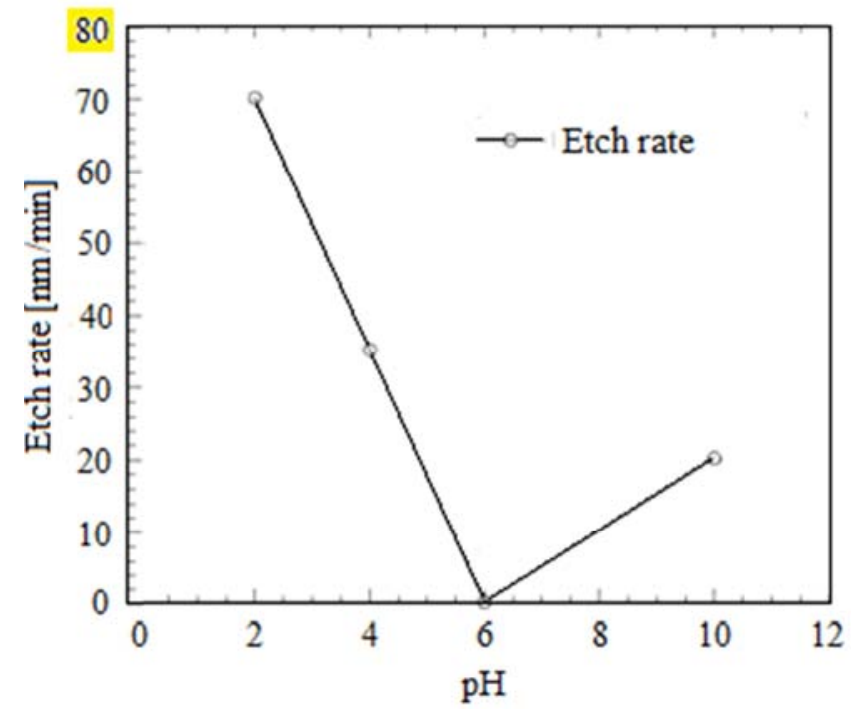

Figure 1. Etch rate of selective layer $\mathrm{CMP}$ in slurries with $6 \% \mathrm{H}_{2} \mathrm{O}_{2}$ at different $\mathrm{pH}$.

It can be noted selective layer etching rate decreased with the increase of $\mathrm{pH}$ and reaches the minimum at $\mathrm{pH} 6$, then, the etching rate starts to increase, with the further increase of $\mathrm{pH}$. A detailed study $[8,9]$ of these structures after CMP with the above slurry has shown low etching and dishing of the selective layer, and no corrosion of the selective layer.

\subsection{Selective Layer Surface Analysis}

After the polishing performance of slurry was determined, selective layer samples were immersed and planarized in slurry mixtures containing different $\mathrm{H}_{2} \mathrm{O}_{2}$ concentrations and pHs and subsequently were examined using XPS.

Figure 2 shows the effect of $\mathrm{H}_{2} \mathrm{O}_{2}$ concentration in the 
slurry on the selective layer etch rate. Initially, the selective layer etches rate increases as the $\mathrm{H}_{2} \mathrm{O}_{2}$ concentration is increased from 0.0 to 2.0 vol. $\% \mathrm{H}_{2} \mathrm{O}_{2}$. However, above 2.0 vol. $\% \mathrm{H}_{2} \mathrm{O}_{2}$, the etch rate begins to drop very rapidly and levels off to a value of about $15 \mathrm{~nm} / \mathrm{min}$ for concentrations of $\mathrm{H}_{2} \mathrm{O}_{2}$ greater than 6.0 vol.\%. This etching behavior is due to an active to the passive transition of the selective layer surface as the $\mathrm{H}_{2} \mathrm{O}_{2}$ concentration in the slurry is increased. For $\mathrm{H}_{2} \mathrm{O}_{2}$ concentrations less than 2.0 vol.\%, the selective layer is active and the etching is controlled by the oxidation rate of the metallic selective layer surface. Above 2.0 vol.\% $\mathrm{H}_{2} \mathrm{O}_{2}$, the selective layer is in its passive state and the etching of the metallic selective layer is likely controlled by ionic diffusion through a passivation layer $[10,11]$.

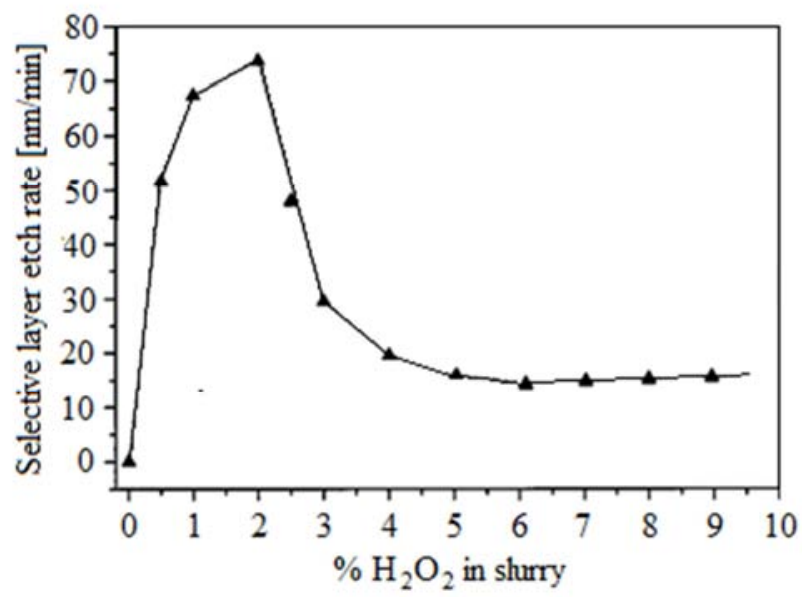

Figure 2. Etch rate of selective layer vs. $\mathrm{H}_{2} \mathrm{O}_{2}$ concentration in slurry at a pH4.

In order to establish the chemical composition of the passivation layer and better understand the etch rate behavior of Figure 3, selective layer samples were exposed to the individual chemical components present in the slurry mixture and analyzed using XPS.

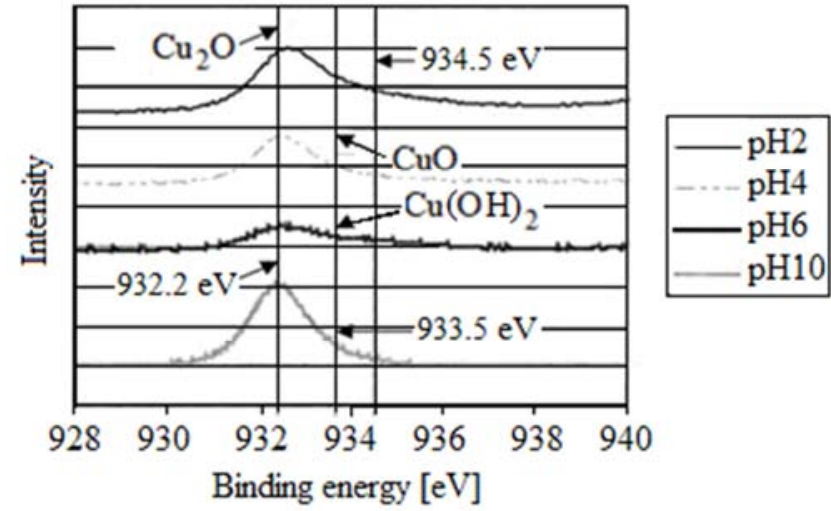

Figure 3. Selective layer copper XPS of copper oxide films formed in solutions with $6.0 \% \mathrm{H}_{2} \mathrm{O}_{2}$ at different $\mathrm{pHs}$ after 10 min of immersion.

Figure 3 shows the XPS spectra for selective layer copper in $\mathrm{pH} 2,4,6$ and 10 solutions after $10 \mathrm{~min}$ of immersion. The characteristic binding energy $(\mathrm{BE})$ value of $\mathrm{Cu}_{2} \mathrm{O}$ at $932.2 \mathrm{eV}$ was observed for samples of all four $\mathrm{pHs}$. The relative high photoelectron signal intensity of $\mathrm{pH} 2$ and $\mathrm{pH} 10$ samples compared to $\mathrm{pH} 4$ and $\mathrm{pH} 6$ indicated the signals possibly responded not only from $\mathrm{Cu}_{2} \mathrm{O}$ on the surface but also from the substrate metallic selective layer.

The deconvolution of the XPS spectra reveals two additional peaks presented at $933.5 \mathrm{eV}$ and $934.5 \mathrm{eV}$ for samples of $\mathrm{pH} 2$ and $\mathrm{pH} 6$. The $\mathrm{BE}$ of selective layer copper in $\mathrm{CuO}$ and $\mathrm{Cu}(\mathrm{OH})_{2}$ are about $933.4 \pm 0.2 \mathrm{eV}$ and $934.5 \pm$ $0.2 \mathrm{eV}$ respectively $[12,13]$. The signals of $\mathrm{CuO}$ could be identified clearly for the sample of pH6.

The samples immersed in the slurry with $\mathrm{pH} 4$ showed a strong peak from selective layer substrate which implies the oxide film formed at this condition is pretty thin. For the sample of $\mathrm{pH} 6$, a spectrum similar to that for the $\mathrm{pH} 2$ sample was observed, both showing strong $\mathrm{Cu}_{2} \mathrm{O}$ signals. The formation of a continuous layer of $\mathrm{CuO}$ can result in passivation and protect the surface from corrosion. For the pH 10 sample, the spectrum shows a strong $\mathrm{Cu}_{2} \mathrm{O}$ signal overlapped with a weak selective layer copper signal from substrate. The relative strong signal for $\mathrm{pH} 10$ sample might indicate that a thicker film formed. The results of the above XPS studies are summarized in Figure 4.

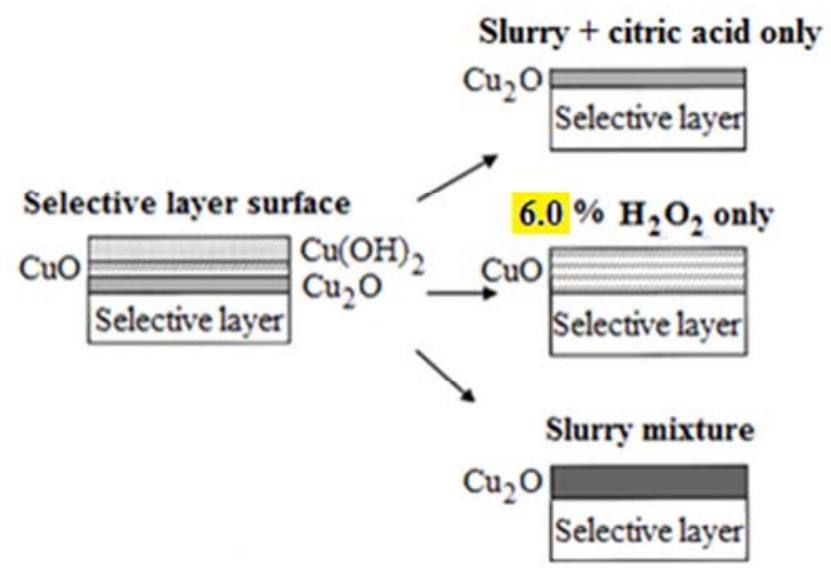

Figure 4. Schematic summarizing the surface analysis results of Figure 3.

When the sample is exposed to the slurry containing the citric acid only, the selective layer oxide and selective layer hydroxide films are dissolved in solution. No etching of the metallic selective layer occurs because there is no oxidation of the selective layer and the $\mathrm{Cu}_{2} \mathrm{O}$ is not dissolved at the $\mathrm{pH} 4$ of the slurry. If the sample is exposed to an oxidizer only 6.0 vol. $\% \mathrm{H}_{2} \mathrm{O}_{2}$, the selective layer hydroxide film initially present on the surface is either converted to $\mathrm{CuO}$ or goes into the solution because of the low $\mathrm{pH}$ of the $\mathrm{H}_{2} \mathrm{O}_{2}$ [14] and the selective layer/ $\mathrm{Cu}_{2} \mathrm{O}$ is oxidized to $\mathrm{CuO}$. Since the $\mathrm{H}_{2} \mathrm{O}_{2}$ has a $\mathrm{pH} 4$, the $\mathrm{CuO}$ is not dissolved [14] and a thick $\mathrm{CuO}$ layer is formed. There is no etching of the selective layer because the thick $\mathrm{CuO}$ passivates the metallic selective layer and prevents further oxidation. For the case when both slurry components (citric acid and $\mathrm{H}_{2} \mathrm{O}_{2}$ ) are mixed in solution, the selective layer is etched because there is 
continuous oxidation of selective layer and $\mathrm{Cu}_{2} \mathrm{O}$. So, the etching is a reaction product and was inferred from changes in the color of the etching solution during the $\mathrm{H}_{2} \mathrm{O}_{2}$ concentration experiments. At low percent of $\mathrm{H}_{2} \mathrm{O}_{2}$ in the slurry, it was noted that the color of the etching solution went from being initially colorless to having a light blue hue during the experiment while at higher $\mathrm{H}_{2} \mathrm{O}_{2}$ concentrations no visible changes from the initial conditions were observed.

The effects of varying the $\mathrm{H}_{2} \mathrm{O}_{2}$ concentration in the slurry on $\mathrm{Cu}_{2} \mathrm{O}$ formation are shown in Figure 5, where the intensity of $\mathrm{Cu}_{2} \mathrm{O}$ relative to the metal selective layer is plotted with the error bars indicating the variability in the data.

The selective layer samples used in this experiment were exposed to the same range of $\mathrm{H}_{2} \mathrm{O}_{2}$ concentrations in the slurry as in the experiment of Figure 2. The contributions from cupric species in selective layer were absent when the sample was exposed to an oxidizer-citric acid mixture. On the other hand, Figure 5 shows that the intensity of $\mathrm{Cu}_{2} \mathrm{O}$ relative to the metallic selective layer increases linearly with the percent of $\mathrm{H}_{2} \mathrm{O}_{2}$ at first and starts to saturate at $\mathrm{H}_{2} \mathrm{O}_{2}$ concentrations of 6.0 vol.\%. These surface analysis results are consistent with the etch rate data of Figure 2. The oxide passivates the metallic selective layer surface and drastically reduces the metallic selective layer etch rate at high $\mathrm{H}_{2} \mathrm{O}_{2}$ concentrations.

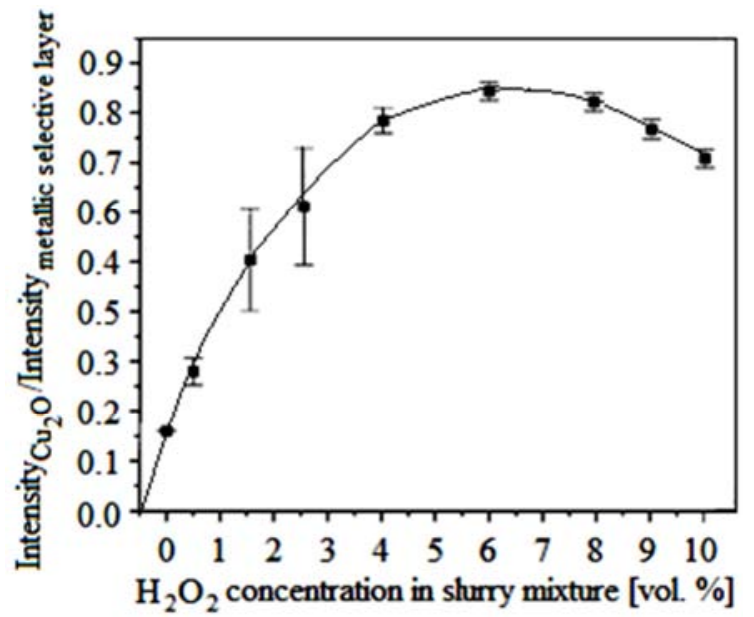

Figure 5. Ratio of the $\mathrm{Cu}_{2} \mathrm{O}$ to metallic selective layer XPS intensity for samples that were dipped in slurry mixtures with a constant $\mathrm{pH} 4$ containing different $\mathrm{H}_{2} \mathrm{O}_{2}$ concentrations.

To observe the effects of $\mathrm{H}_{2} \mathrm{O}_{2}$ concentration in the slurry on the removal of selective layer, the etch rate of selective layer was measured as a function of $\mathrm{pH}$ at two different percentages of $\mathrm{H}_{2} \mathrm{O}_{2}$ concentrations. Figure 6 shows that the selective layer etches rates at 2.0 and 6.0 vol. $\% \mathrm{H}_{2} \mathrm{O}_{2}$ in slurry decrease with increasing pH. At 2.0 vol. $\% \mathrm{H}_{2} \mathrm{O}_{2}$, the decreasing in the etching rate with increasing $\mathrm{pH}$ can be explained by the increase in the amount of $\mathrm{Cu}_{2} \mathrm{O}$ present on the selective layer surface, justified by peak growth at $\mathrm{BE}$ of $932.2 \mathrm{eV}$ (see Figure 3).

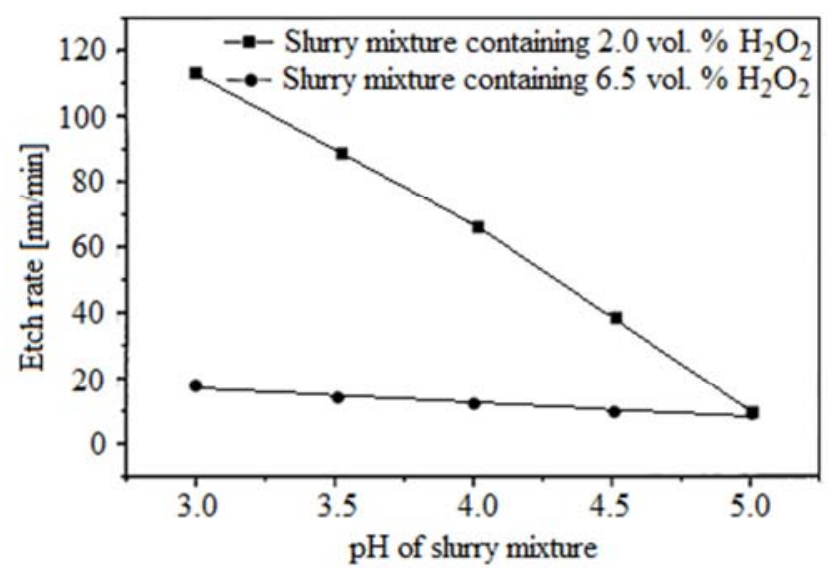

Figure 6. Etch rate vs. $\mathrm{pH}$ at 2.0 and 6.5 vol.\% $\mathrm{H}_{2} \mathrm{O}_{2}$ slurry mixtures.

The greater amount of $\mathrm{Cu}_{2} \mathrm{O}$ protects or passivates the metal surface with selective layer and reduces the oxidation rate of the metallic selective layer at higher $\mathrm{pH}$ values. A similar trend is seen when the selective layer is exposed to a slurry mixture containing 6.0 vol. $\% \mathrm{H}_{2} \mathrm{O}_{2}$, where there is very little change both in the etch rate and in the amount of $\mathrm{Cu}_{2} \mathrm{O}$ present on the surface with varying $\mathrm{pH}$.

The difference in the etches rates of the samples exposed to the two oxidizer concentrations is most likely due to a thicker and more uniform $\mathrm{Cu}_{2} \mathrm{O}$ layer present on the surface when the selective layer is exposed to the slurry mixture containing 6.0 vol. $\% \mathrm{H}_{2} \mathrm{O}_{2}$. It is not clear why the etch rates at $\mathrm{pH} 5$ are similar for both oxidizer concentrations, but the presence of $\mathrm{CuO}$ and $\mathrm{Cu}(\mathrm{OH})_{2}$ at this slurry $\mathrm{pH}$ in both cases may provide an additional layer of protection to more effectively reduce the oxidation of the metallic selective layer.

The selective layer etching study showed that the removal

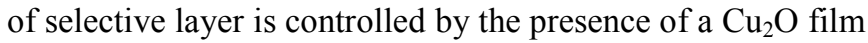
which becomes passivating at high $\mathrm{H}_{2} \mathrm{O}_{2}$ concentrations and high $\mathrm{pH}$. The problem is, if for CMP conditions, the removal of the selective layer is controlled by an abrasion repassivation process whereby the $\mathrm{Cu}_{2} \mathrm{O}$ passive film is continually polished by the mechanical action allowing the oxide-free surface to quickly oxidize or re-passivate.

The reactions that take place at the metallic selective layer/liquid interface increase the oxidation state of the selective layer in the slurry mixture. When the concentration of $\mathrm{H}_{2} \mathrm{O}_{2}$ in the slurry is varied, Figure 2 indicates that selective layer etches more rapidly at low $\mathrm{H}_{2} \mathrm{O}_{2}$ concentrations. Although the results of Figure 5 show that $\mathrm{Cu}_{2} \mathrm{O}$ is present on the surface when the concentration of $\mathrm{H}_{2} \mathrm{O}_{2}$ in the slurry is low, the XPS measurements do not allow us to answer the question if the $\mathrm{Cu}_{2} \mathrm{O}$ layer is continuous [13]. It is likely that the formation of $\mathrm{Cu}_{2} \mathrm{O}$ layers at low $\mathrm{H}_{2} \mathrm{O}_{2}$ concentration is incomplete and offers no protection against oxidation. Hence, at low $\mathrm{H}_{2} \mathrm{O}_{2}$ concentrations, the metallic selective layer is in its active state and the etching of the metallic selective layer is limited by the rate of the oxidation reaction, which is a function of concentration in the slurry mixture. 
At higher concentrations ( $>2.0$ vol.\%), a uniform $\mathrm{Cu}_{2} \mathrm{O}$ layer is likely to present, and so can limit the oxidation reaction and restrains the etching of the selective layer. At 6.0 vol.\% $\mathrm{H}_{2} \mathrm{O}_{2}$, the thinning of the $\mathrm{Cu}_{2} \mathrm{O}$ layer is possible and therefore higher etching rates. When the selective layer sample is planarized a different scenario is present.

At low $\mathrm{H}_{2} \mathrm{O}_{2}$ concentration, the XPS results show that the primary species present during selective layer CMP is $\mathrm{Cu}(\mathrm{OH})_{2}$ and $\mathrm{CuO}$. At higher $\mathrm{H}_{2} \mathrm{O}_{2}$ concentrations, a $\mathrm{CuO}$ film which is less soluble than the $\mathrm{Cu}(\mathrm{OH})_{2}$ is also present on the metallic selective layer surface during planarizing. Hence, in selective layer CMP, the removal of the selective layer is determined by the oxidation of the metallic selective layer and by the solubility of a cupric film $\left(\mathrm{Cu}(\mathrm{OH})_{2}\right.$ or $\mathrm{CuO})$.

These observations indicate that CMP slurries must remain stable during polishing to obtain optimal planarizing performance.

Also, in CMP processes, polishing slurries have to be stabilized under extreme environments of $\mathrm{pH}$, strength, pressure, and temperature, in the presence of reactive additives. An alternative is to use surfactant at the solidliquid interface for the stabilization of particulate systems [15-21]. It is known that the presence of surfactants can result in lubrication between the abrasive and the surface to be polished $[22,23]$. The surface quality was observed to be optimal with minimal surface roughness and deformation $[24,25]$.

\section{Conclusions}

The present paper has shown that the removal of the selective layer during etching and CMP is affected by the presence of selective layer oxides on the surface.

Surface analysis revealed the presence of $\mathrm{Cu}_{2} \mathrm{O}$ on the selective layer surface after dipping selective layer samples in a slurry containing $\mathrm{H}_{2} \mathrm{O}_{2}$ and a citric acid. The thickness of the $\mathrm{Cu}_{2} \mathrm{O}$ film increased with increasing $\mathrm{H}_{2} \mathrm{O}_{2}$ concentration reducing the etch rate of the selective layer at sufficiently high concentrations.

For planarizing of selective layer, the surface analysis revealed the presence of $\mathrm{CuO}$ and $\mathrm{Cu}(\mathrm{OH})_{2}$ on the metallic selective layer surface. The amount of $\mathrm{CuO}$ on the surface increased with increasing $\mathrm{H}_{2} \mathrm{O}_{2}$ concentration in the slurry limiting the removal of the selective layer. When the $\mathrm{pH}$ of the slurry mixture was varied, the etching rate decreased with increasing $\mathrm{pH}$, slow, at high $\mathrm{H}_{2} \mathrm{O}_{2}$ concentrations and faster, at low $\mathrm{H}_{2} \mathrm{O}_{2}$ concentrations.

This difference with $\mathrm{H}_{2} \mathrm{O}_{2}$ concentration has been attributed to the presence of a $\mathrm{CuO}$ film which is present at 6.0 vol. $\% \mathrm{H}_{2} \mathrm{O}_{2}$ but not at 2.0 vol. $\% \mathrm{H}_{2} \mathrm{O}_{2}$.

The removal of the selective layer during CMP for the particular slurry mixture used in this paper appears to be determined by the oxidation rate of the metallic selective

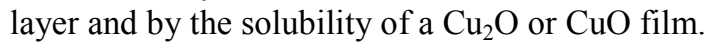

In CMP, the slurry mixture has a significant effect on the process performance and should be carefully monitored for optimal results. Slurry chemistry has to be tailored so that the slurry to be stable for to obtain the optimal surface quality.

The solution is the use of surfactants to stabilize the slurry in extreme environments.

The etching and removal rates by CMP of the selective layer in slurries with $6.0 \% \mathrm{H}_{2} \mathrm{O}_{2}$ were found to vary with $\mathrm{pH}$. Corrosion products formed on selective layer surface were found to be responsible for this CMP removal rate.

\section{References}

[1] F. Ilie, Study tribological of thin superficial layers formed in the friction couples through selective transfer, 2002 (Technical Publishing House, Bucharest).

[2] F. Ilie and C. Tita, Comparative analysis of tribological performances of materials that can achieve thin layers from selective transfer. J. Balkanical Tribol. Assoc., 2006, 12(4), 404-411.

[3] D. N. Garkunov, Erhonung der Verschleissfestigkeit auf der selektiven Ubertragung, 1981 (VEB Verlag Technik, Berlin).

[4] S. P. Murarka, Chemical-Mechanical Polishing Fundamentals and Challenges, edited by S. V. Babu, S. Danyluk, M. I. Krishnan, and M. Tsujimura, Mater. Res. Soc. Proc. 566 (2000), p. 3.

[5] J. Hernandez, P. Wrschka, and G. S. Oehrleinc, Surface Chemistry Studies of Copper Chemical Mechanical Planarization, Journal of The Electrochemical Society, 148(7), G389-G397 (2001).

[6] F. Ilie and G. Ipate, Chemical-Mechanical Impact of Nanoparticles and pH Effect of the Slurry on the CMP of the Selective Layer Surfaces, Lubricants, 5(2), 15 (2017).

[7] M. Bielman, Chemical Mechanical Polishing of Tungsten, University of Florida Master Thesis (1998).

[8] M. S. Gaither, R. S. Gates, R. Kirkpatrick, R. F. Cook, and F. W. Del Rio, Etching Process Effects on Surface Structure, Fracture Strength, and Reliability of Single-Crystal Silicon Theta-Like Specimens, Journal of Micro-electromechanical Systems, 22(3), 589-602 (2013).

[9] F. Ilie and T. Laurian, Investigation into the Effect of Concentration of Benzotriazole on the Selective Layer Surface in the Chemical Mechanical Planarization Process, Journal of Materials Engineering and Performance, 24(12), 4919-4927 (2015).

[10] V. Brusic, M. Frisch, B. Eldrige, F. P. Novak, F. B. Kaufman, B. Rush, and G. S. Frankel, J. Copper corrosion with and without inhibitors, Electrochem. Soc., 138, 2253 (1991).

[11] M. Pourbaix, Atlas of Electrochemical Equilibria in Aqueous Solutions, 1st ed., Pergamon Press Ltd., Oxford (1966).

[12] N. S. Mcintyre, S. Sunder, D. W. Shoesmith and F. W. Stanchell, Chemical information from XPS - applications to the analysis of electrode surfaces, J. Vac. Sci. Technol., 18, 714 (1981).

[13] S. K. Chawla, B. I. Rickett, N. Sankarraman, and J. H. Payer, An X-ray photo-electron spectroscopic investigation of the air-formed film on copper, Corros. Sci., 33, 1617 (1992). 
[14] T. Du, A Vijayakumar, V Desai, Effect of hydrogen peroxide on oxidation of copper in CMP slurries containing glycine and $\mathrm{Cu}$ ions, Electrochimica Acta,. 49 (25), 4505-4512 (2004).

[15] Y. Xie and B. Bhushan, Effects of particle size, polishing pad and contact pressure in free abrasive polishing, Wear, 200, p. 281 (1996).

[16] J. Luo, D. A. Dornfeld, Effects of Abrasive Size Distribution in Chemical Mechanical Planarization: Modeling and Verification, IEEE Transactions on Semiconductor Manufacturing, vol. 16, no. 3, 469 (2003).

[17] M. Colic, D. W. Fuerstenau, Influence of the dielectric constant of the media on oxide stability in surfactant solutions, Langmuir, 13, 6644 (1997).

[18] M. J. Solomon, T. Saeki, M. Wan, P. J. Scales, D. V. Boger, H. Usui, Effect of adsorbed surfactants on the rheology of colloidal zirconia suspensions, Langmuir, 15, 20 (1999).

[19] L. K. Koopal, T. Goloub, A. deKaiser, M. P. Sidorova, The effect of cationic surfactants on wetting, colloid stability and flotation of silica, Colloids Surf., 151, 15 (1999).

[20] K. E. Bremmel, G. J. Jameson, S. Biggs, Adsorption of ionic surfactants in particulate system: flotation, stability, and interaction forces, Colloids Surf., 146, 755 (1999).

[21] C. R. Evanko, D. A. Dzombak, J. W. Novak, Influence of surfactant addition on the stability of concentrated alumina disspersions in water, Colloids Surf., 110, 219 (1996).

[22] J. J. Adler, P. K. Singh, A. Patist, Y. I. Rabinovich, D. O. Shah and B. M. Moudgil., Correlation of particulate dispersion stability with the strength of self-assambled surfactant films, Langmuir, 16, 7255-7262 (2000).

[23] G. B. Basim, I. U. Vakarelski, B. M. Moudgil, Role of interaction forces in controlling the stability and polishing performance of CMP slurries, Journal of Colloid and Interface Science, vol. 263 (2), 506-515 ( 2003).

[24] M. C. Pohl, D. A. Griffith, The importance of particle size to the performance of abrasive particles in the CMP processes, J. Electron. Mater., vol. 25, pp. 1612-1616 (1996).

[25] G. B. Basim, J. J. Adler, U. Mahajan, R. K. Singh, Effect of particle size of chemical mechanical polishing slurries for enhanced polishing with minimal defects, J. Electrochem. Soc., vol. 147(9), 3523-3528 (2000). 